\title{
The relationships between effective porosity, uniaxial compressive strength and sonic velocity of intact Borrowdale Volcanic Group core samples from Sellafield
}

\author{
D. C. Entwisle, P.R.N. Hobbs, L.D. Jones, D. Gunn and M.G. Raines
}

British Geological Survey, Keyworth, Nottingham NG12 5GG.

\begin{abstract}
The effective porosity, saturated sonic velocity and saturated uniaxial compressive strength were determined on a large number of Borrowdale Volcanic Group volcaniclastic core samples from three boreholes at Sellafield, Cumbria. The worked formed part of the UK Nirex Limited site investigation into whether the Sellafield area could be suitable as a repository for intermediate and low level radioactive waste. Most of the intact samples were of low to very low effective porosity, had a high sonic velocity and were very strong to extremely strong. However, a proportion of values deviated significantly from this. Bivariate analysis showed a negative relationship exists between sonic velocity and effective porosity. The cross plots of these two parameters with uniaxial compressive strength showed a wide range of strength values for samples of low effective porosity and high sonic velocity.

Six failure types were identified during the uniaxial compressive strength tests. The strongest samples tended to fail through the matrix and the weakest rock samples tended to fail through haematized material or along haematized veins. Effective porosity and sonic velocity measurements could not distinguish between those samples that failed through the matrix and those that failed along discrete narrow veins. The presence of narrow haematized veins has a major effect on the intact rock strength.
\end{abstract}

\section{INTRODUCTION}

Underground disposal of radioactive waste was contemplated in the vaults of an engineered repository in a low permeability host formation, (Davies \& Mellor 1996). As part of the UK Nirex off-site core characterisation programme core was gathered from the host rock-mass for laboratory tests to provide key data to evaluate the performance of the engineered structure during construction and operation phases, (NIREX, 1997a). This included geotechnical and geophysical measurements on intact rock samples of Borrowdale Volcanic Group (BVG) from the Sellafield area, Cumbria, North-West England. The results presented are effective porosity, uniaxial compressive strength and sonic velocity of samples from Nirex's Sellafield Boreholes 2, 4 and 5, the deep boreholes from the potential repository zone (PRZ) (Figure 1). These data provided basic geophysical and geotechnical property information of the intact rock. Effective porosity and sonic velocity data were used to aid the calibration and interpretation of the downhole wireline geophysical logs for the investigation 
of the spatial variability of rock mass properties in the PRZ (NIREX, 1997b). The uniaxial compressive strength data provided index values for rock mass rating systems, the unconfined value in triaxial compression tests (used to establish the triaxial failure envelope and quantifying failure criterion for intact rock) and to compare with downhole wireline geophysical logs (NIREX, 1997b, Brereton et al., 1998). This required a large number of tests and over two hundred and fifty effective porosity and sonic velocity and over one hundred and fifty uniaxial compressive strength tests were carried out on core from the three boreholes.

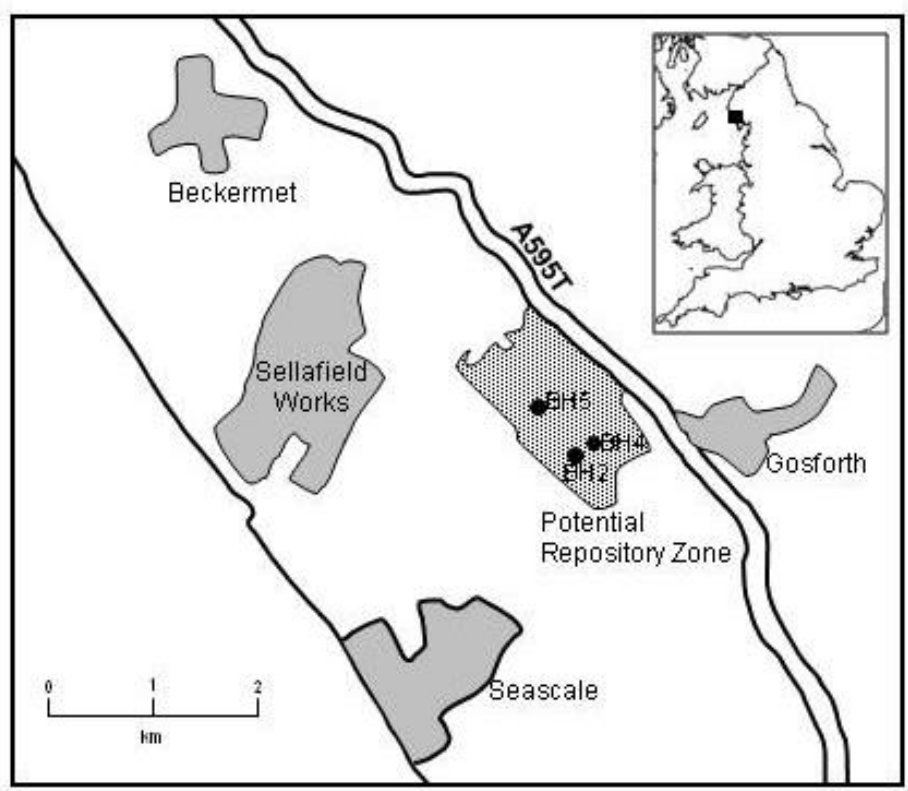

Figure 1. Location of the Nirex deep boreholes in the potential repository zone of the Sellafield area.

Rock porosity can be determined from a number of down-hole logs. Normally this is done with the neutron 'porosity' logging tool by applying various corrections to compensate for incorporating 'bound' water of crystallisation. Resistivity, density and sonic velocity logs are also used. The sonic velocity of a rock increases with decreasing effective porosity. The sonic tool response is affected by the formation porosity, fluid and matrix; if these properties and degree of saturation are known or can be determined, the tool response can be related to porosity. The porosity may be determined from the sonic logs using the Wyllie time-average equation in which porosity is directly proportional to the inverse of the sonic velocity (Wood, 1941). This equation is usually used for clean and cemented formations, with uniformly distributed small pores and moderate porosity (Schlumberger, 1989). More complex formulae have been developed to relate a wider range of porosity to sonic velocity Brereton \& McCann (1990) and Brereton (1992). However, as sonic velocity of the rock mass is also affected by 
discontinuities caused for example by fractures, jointing and infilled mineral veins, it can be used as a part of the assessment of the rock mass such as Rock Quality Designation (RQD) (Glenn \& Nelson, 1979, McCann 1990). McCann et al. (1981) introduced the concept of a simplified rock mass classification system based on the dynamic bulk modulus of the rock mass from sonic and shear velocity.

Differences are expected between rock property measurements made on core samples in the laboratory and those derived from wireline logging tools in a borehole. The effects of scale are important when comparing borehole and laboratory measurements, and relate to the volume and condition of the rock mass sampled during measurement. The laboratory samples are essentially point data from known depths. A number of tests may be carried out on the same core specimen under known conditions. The fabric of the test specimen can be described and any influences on the test results, such as mineral veins or alteration products. However, the volume of laboratory samples are small and distance between tests much greater than in wireline logs which may have a sample size of 5 to $10 \mathrm{~m}^{3}$ and sampling intervals of about $15 \mathrm{~cm}$, providing a nearly continuous downhole profile under in situ conditions (Brereton et al., 1998). Also, material for laboratory testing may be restricted due to drilling disturbance, and samples failing during preparation. This tends to bias the results in favour of stronger more competent material and against highly altered very weak to weak rock.

Improved assessments of the engineering performance of the Borrowdale Volcanic Group can be gained from a greater understanding of formation rock mass properties and also any relationship between individual properties of the intact rock matrix. To this end, data from the laboratory tests described in this paper have been analysed for a series of relationships between the parameters including effective porosity, sonic velocity, effective porosity and uniaxial compressive strength. The relationship between uniaxial compressive strength and sonic velocity was investigated by D'Andrea et al (1965) for various rock types from the United States of America and by McCann et al (1990) for a wide range of British rock types. McCann et al. (1990) found a good coefficient of regression ( $\mathrm{r}^{2}$ of 0.88, 150 data points) for a power model $\left(y=a x^{b}\right)$. However, the individual points were well scattered, particularly at low porosity values. The variation in strength at low effective porosity and high sonic velocity may be due to differences in fabric and texture and, in some rocks, mineral veins will also affect the rock strength. 
The paper presents a number of bivariate plots and relationships for the laboratory effective porosity and sonic velocity, sonic velocity and uniaxial compressive strength and, effective porosity and uniaxial compressive strength. The effects of mineral veins and alteration products on the behaviour of the BVG are also considered.

\section{GEOLOGY}

The rocks of the Borrowdale Volcanic Group, in the three boreholes (Boreholes 2, 4, 5, see Figure 1), are dominated by a highly complex and variable sequence of pyroclastic flow deposits with minor thicknesses of volcaniclastic sedimentary rocks and intrusive andesite. The formations and members encountered in each borehole are listed with depths (in maOD) in Table 1 (Ambrose et al., 1992a, b; Millward et al., 1992). A summary of the geology is in Millward et al. (1994) and Michie (1996).

Typically, the Fleming Hall Formation comprises massive, homogeneous, geochemically uniform, andesitic, mainly densely welded tuff and lapilli tuff. Breccia and volcanic sediments as rocks are also present as minor components. There are also zones of alteration and faulting within this formation. The Brown Bank Formation comprises relatively thin ignimbrite sheets; the lower part is often brecciated. The Bleawath Formation is made up of two or three welded ignimbrite sheets each separated by a generally thin layer of volcanic sandstones. Borehole 2 contains two other Formations: the Broom Farm Formation and the Moorside Farm Formation. The former is a massive to medium to thickly bedded, red, coarse-grained and pebbly volcanic sandstone, and the latter is a massive, unbedded, poorly sorted, lapilli tuff and matrix- to clast-supported coarse breccia. The intrusive rocks are usually andesitic but in Borehole 4 the upper intrusive sheets are basalt or basaltic andesite.

Within the Borrowdale Volcanic Group there are zones of alteration that contain variable amounts of haematized material and veins. A secondary mineral assemblage variably replaces the primary minerals and includes sericite, chlorite, haematite and carbonate. Some sections are extensively veined and the mineralogy of the veins includes carbonate, epidote, feldspar and haematite veins. This is most noticeable in fault zones, but reddened and haematized and grossly altered and fractured rock occur at various levels within each borehole. 
In Borehole 2 the main zones of alteration are indicated by fracturing and reddening. Within the Fleming Hall Formation the fault zones are at -562 to $-588 \mathrm{maOD},-728.3 \mathrm{maOD}$ and -798.5 to -807 maOD. The Brown Bank Formation is locally reddened, haematized and grossly altered with many fractures notably at the top and reddening occurs at some levels throughout. The base of the formation consists of haematized, heterolithic volcanic sedimentary rock. The Bleawath Formation in this borehole is characterised by systematic chemical zonation. Reddened zones occur at the top, in a volcanic sandstone, and in other zones elsewhere (Ambrose et al., 1992a).

Many haematized and carbonate-filled steep faults and veins have been identified in the Borrowdale Volcanic Group of Borehole 4, particularly within the Fleming Hall Formation. Some faults are sheared and slickensided. Faults in the Brown Bank and Bleawath Formations contain narrow shear zones with mylonitic material. Within the Longlands Farm Member, from -530 to $-684 \mathrm{maOD}$, is an extensively altered tuff. A fine, steeply dipping, millimetre-scale, mesh-like pattern pervades the rock, obliterating the original texture throughout much of the sequence. The unit contains many, generally narrow, faults.

The rocks of the Fleming Hall Formation in borehole 5 contain zones of intensive but intermittent alteration from -424.5 to $-454.5 \mathrm{maOD}$ and -479.5 to $-499.5 \mathrm{maOD}$. The rock is faulted and has a fine, steeply dipping, millimetre-scale, mesh-like pattern. The lower part of the Brown Bank Formation is totally brecciated and the middle of the Bleawath Formation contains irregular veins with medium to coarse-grained tuff and fine breccia. The associated fractures are commonly filled with chlorite and some sulphide mineralisation.

\section{TEST METHODS}

Most of the samples selected were either typical of the formation or adjacent core and includes core from more altered rock. Damaged core and core that could not be prepared was not selected. Test samples were prepared from full diameter core lengths of 20 to $25 \mathrm{~cm}$. The average sampling distance was about $10 \mathrm{~m}$. Uniaxial compressive strength tests were carried out at an average of one test per $17 \mathrm{~m}$.

Two right-cylinder specimens, nominally $38 \mathrm{~mm}$ in diameter and $76 \mathrm{~mm}$ long were prepared from each piece of selected core. This allowed two side-by-side specimens to be prepared parallel to the borehole axis from the original $95 \mathrm{~mm}$ diameter core. Density and porosity determinations were carried out on one sample and the other was used for a variety of tests 
including sonic velocity and uniaxial compressive strength test as required. The ends of each sample were surface ground to be flat and parallel within $20 \mu \mathrm{m}$. Some saturated uniaxial compressive strength determinations were carried out on full diameter core, nominally 95 $\mathrm{mm}$ in diameter and over $190 \mathrm{~mm}$ in length. The uniaxial compressive strengths of these samples were similar to the values for the smaller samples.

\section{Laboratory determinations}

Effective porosity, uniaxial compressive strength and sonic velocity test methods were based on Anon. (1981). The effective porosity is the volume of interconnected pore space to the bulk volume and is expressed as a percentage. It was determined using the vacuum saturation and buoyancy technique and is usually reported to $0.1 \%$, however they are reported to $0.01 \%$ here. This has little effect on the bivariate analysis. Sonic velocity and uniaxial compressive strength samples were vacuum saturated and surface dried with a damp cloth prior to testing. The laboratory and wireline sonic velocity tests employ essentially the same basic principles in that an acoustic source transmits sonic wave impulses into the rock, which are monitored for their arrival time, after transit over a known distance through the rock. The laboratory measurements were made with a portable ultrasonic apparatus.

The strength classification used is from Anon. (1999). Two hundred and seventy seven effective porosity, one hundred and seventy seven uniaxial compressive strength and two hundred and sixty one sonic velocity test were successfully completed on core from the three boreholes.

\section{Statistical analysis}

The analysis of the data was carried out in two ways: by bivariate plotting, regression and correlation analysis and by use of percentiles and box and whisker plots. The regression lines were calculated using the least-squares technique and applied to the three relationships: uniaxial compressive strength vs. effective porosity, uniaxial compressive strength vs. sonic velocity and sonic velocity vs. effective porosity. The former of each pair is considered here to be the dependant variable and the latter the independent variable. Four different regression models were used: linear, exponential, $\log _{10}$ and power. The models that had the highest coefficients of regression for each relationship are presented here.

The box and whisker plots were used to compare the medians, upper and lower quartiles, ranges and extreme values of each group. Figure $2 \mathrm{a}$ is a distribution plot of the uniaxial compressive strength data and Figure $2 b$ is the box and whisker plot, which divides the data into four areas of equal frequency. The box encloses the middle fifty percent of values, lower 
and upper quartile. The median is drawn as a horizontal line inside the box. Vertical lines, "whiskers", extend from each end of the box. The lower whisker is drawn from the lower quartile to the smallest data point within 1.5 quartile ranges from the first quartile. The other whisker is drawn from the upper quartile to the highest data point within 1.5 quartile ranges of the upper quartile. Points that lie outside the whiskers are depicted by a plus sign (+).

\section{RESULTS}

The basic statistical data for the effective porosity, uniaxial compressive strength (U.C.S) and sonic velocity are summarised in Table 2 .

There were two hundred and seventy seven effective porosity determinations. The results varied between $0.01 \%$ and $15.7 \%$ with a mean of $0.98 \%$ and median of $0.51 \%$. A majority of the values were less than $1 \%$. These results show that the Borrowdale Volcanic Group is generally low to very low porosity material but there are some samples with higher effective porosities. One hundred and seventy seven uniaxial compressive strength tests were completed on samples of Borrowdale Volcanic Group rock from the three boreholes. The lowest value was 6.1 MPa and the highest value was 496.6 MPa. A majority of the samples were 'very strong' or 'extremely strong' (more than $100 \mathrm{MPa}$ ). However, over a quarter of the samples were 'moderately strong' to 'strong'. Only a few samples had uniaxial compressive strength values of less than $25 \mathrm{MPa}$. The maximum and minimum of the two hundred and sixty one sonic velocity tests were 6.39 and $3.40 \mathrm{~km} / \mathrm{s}$ respectively. The majority of values were greater than $5.75 \mathrm{~km} / \mathrm{s}$. However, about ten percent of values were less than 5 $\mathrm{km} / \mathrm{s}$. 


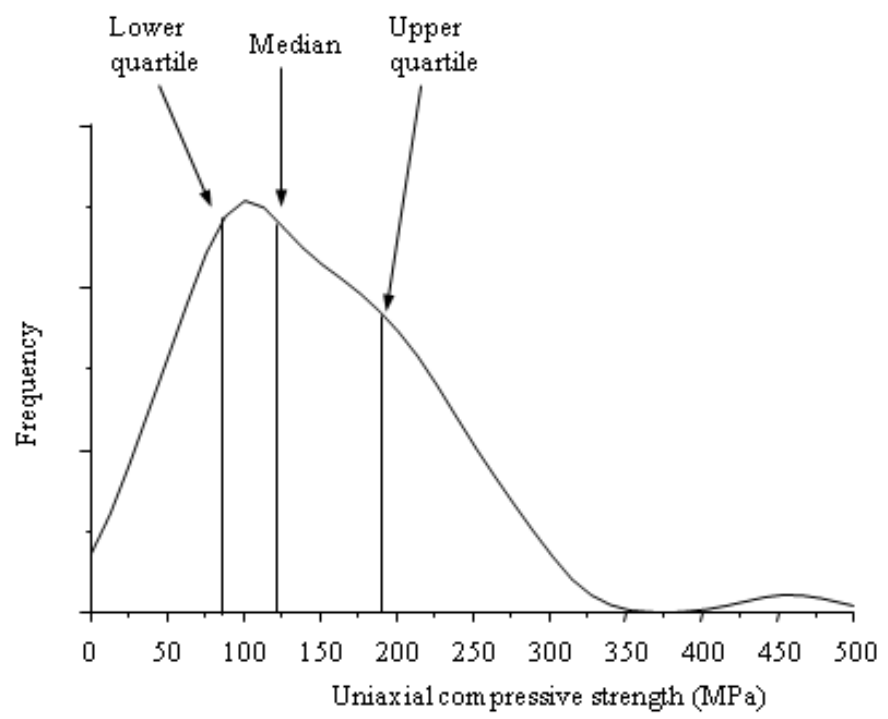

Figure 2a. Density distribution plot of the uniaxial compressive strength data

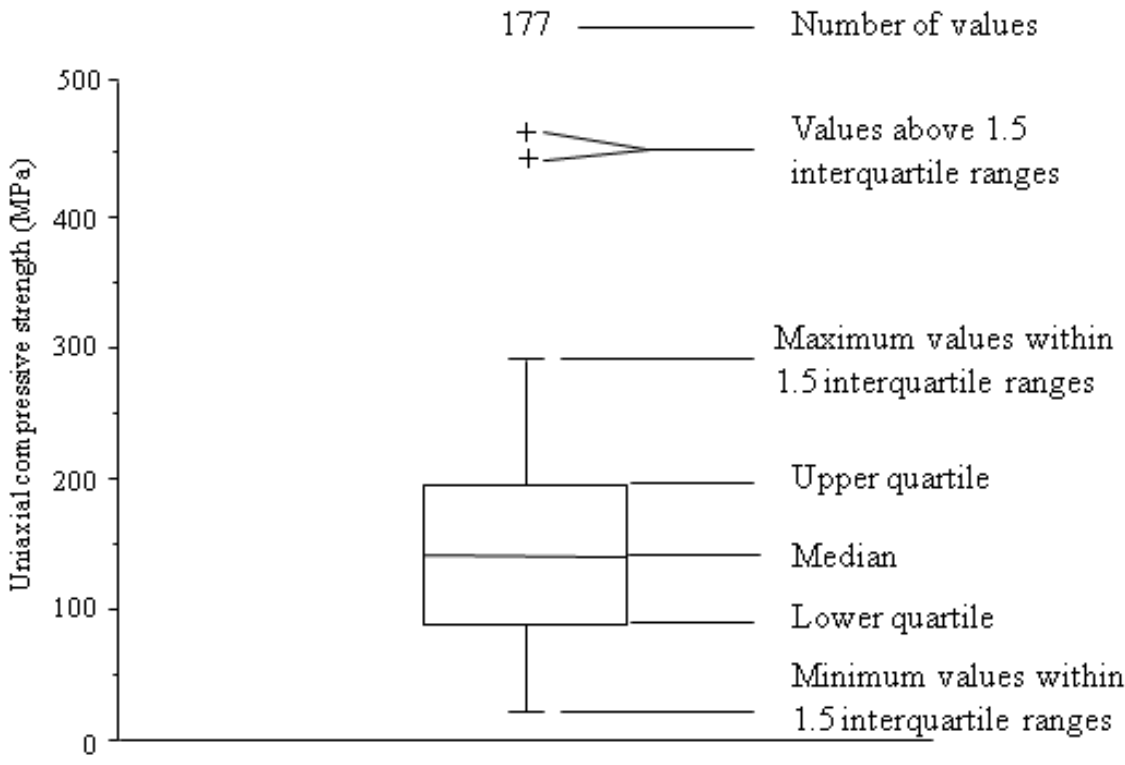

Figure $2 b$. Explanation of $a$ box and whisker plot with the uniaxial compressive strength data.

The data shows that the Borrowdale Volcanic Group is typically low to very low porosity, very strong or extremely strong and of high sonic velocity; however, there are anomalous values for each parameter.

The cross plot of log effective stress and sonic velocity (Figure 3) shows a general trend of increasing sonic velocity with decreasing effective porosity. However, there is little change in sonic velocity when the effective porosity is less than about $0.3 \%$. This is probably due to the sonic wave moving along a shortest path through the rock without encountering any water filled pore. The regression coefficients $\left(\mathrm{r}^{2}\right)$ of the three relationships (Table 3 ) are all above 
0.7 for 256 points. The highest $r^{2}$ value is for the $\log _{10}$ regression line, which is plotted on Figure 3, but this relationship overestimates the values of sonic velocity when the effective porosity is less than about $0.3 \%$.

The results of the sonic velocity and uniaxial compressive strength (Figure 4) confirm the non-linear relationship as shown by D'Andrea et al. (1965) and McCann et al. (1990). The plot suggests that the sonic velocity may be used to find a limiting maximum strength. However, there is a wide scatter, particularly when the sonic velocity is greater than about 5.8 $\mathrm{km} / \mathrm{sec}$ and here samples may be strong, very strong or extremely strong. The exponential relationship has the highest regression coefficient $\left(r^{2}=0.53\right.$ for 142 points). 


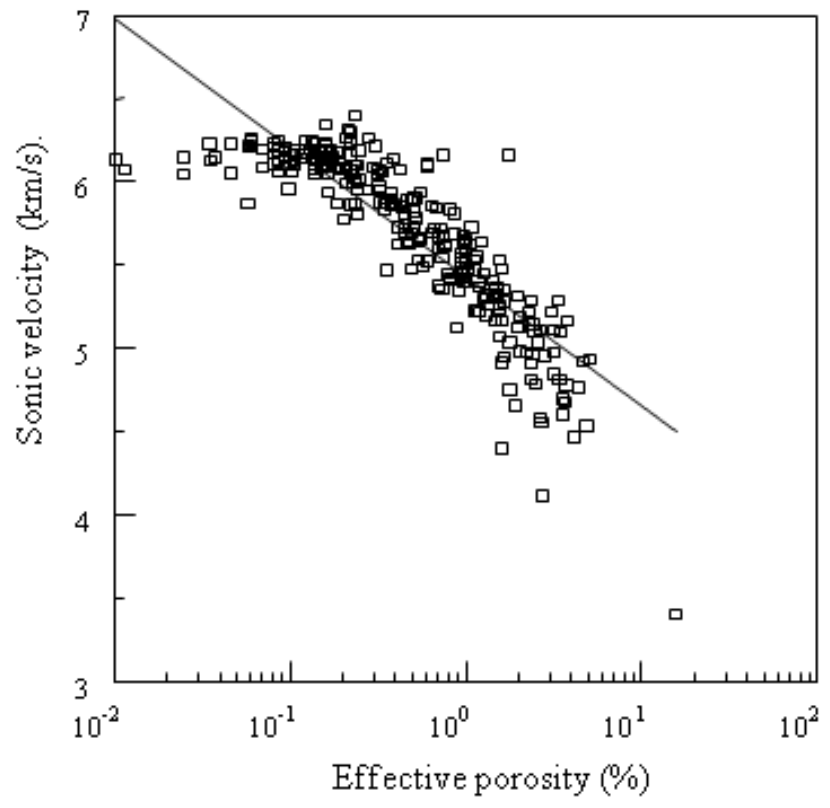

Figure 3. Plot of $\log _{10}$ effective porosity and sonic velocity with a $\log _{10}$ regression line

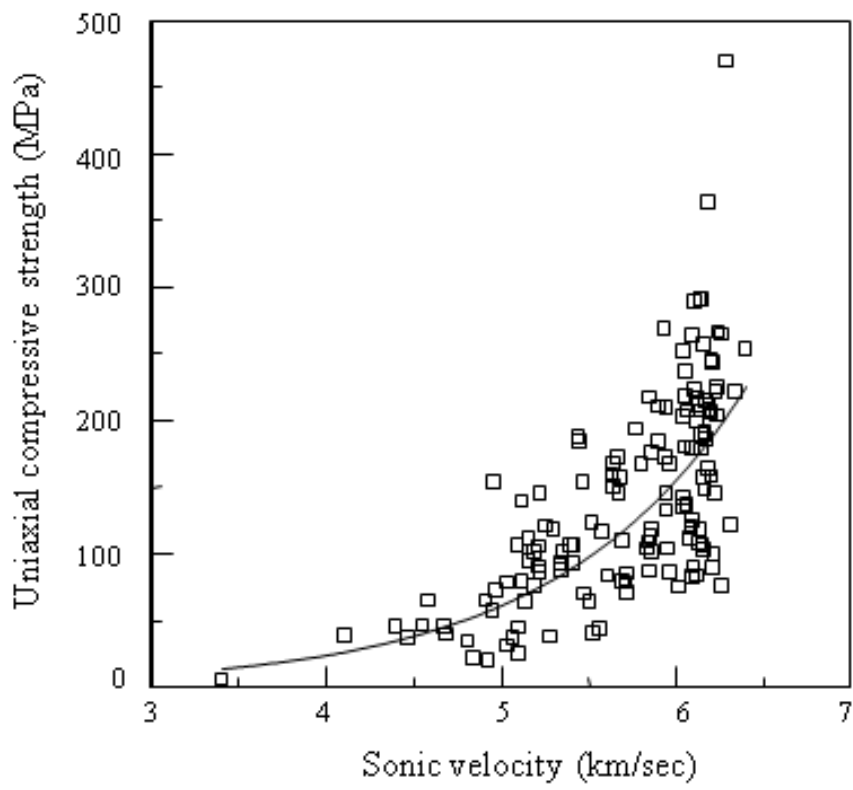

Figure 4. Plot of sonic velocity and uniaxial compressive strength with an exponential regression line.

The plot of effective porosity and $\log _{10}$ uniaxial compressive strength plot (Figure 5) shows a trend of increasing uniaxial compressive strength with decreasing effective porosity but with increasing scatter. Samples with an effective porosity of about $1 \%$ are generally strong to very strong whereas those with an effective porosity of $0.3 \%$ may be strong, very strong or extremely strong. It also indicates a lower boundary and an upper boundary. This is probably 
due to fabric and structural differences between samples. The regression coefficient of the exponential relationship is similar to that of sonic velocity and uniaxial compressive strength $\left(r^{2}=0.53\right.$ for 144 points).

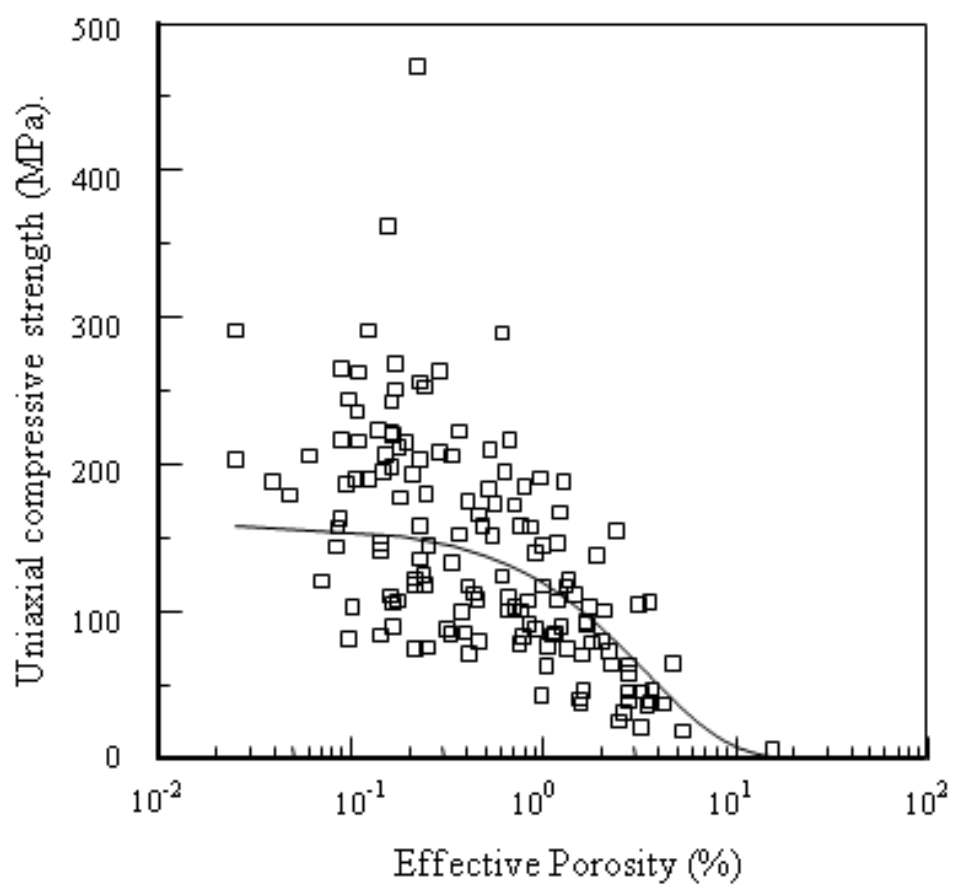

Figure 5. Plot of $\log _{10}$ effective porosity and uniaxial compressive strength with an exponential regression line.

\section{DISCUSSION}

The laboratory data presented here show that the effective porosity can be estimated for a measured sonic velocity. However, uniaxial compressive strength cannot be estimated with any confidence from these two parameters for the low effective porosities and high sonic velocities typical of these rocks. This has major implications for modelling in situ rock strength from downhole wireline geophysical data. Some understanding of this can be gained from observations of how the samples fail and how this relates to the properties of the intact rock

The failed samples were classified by type of material that failed. Six classes were identified:

\section{Class Description}

1 Failed through the matrix of the samples

2 Failed partly along a white vein

3 Failed along white vein

4 Failed along a number of white veins 
5 Failed partly along haematized vein or through haematized zone

6 Failed along haematized vein

The white mineral is predominantly carbonate, either calcite or dolomite but may be quartz in some instances. Class 1 includes samples with white veins along which failure did not occur. Failure along the white veins generally occurs between the vein and the matrix, both of which may be intact. Most of the veins in the samples range from hairline to a millimetre or so in thickness. Failure along haematized veins, and sometimes through a haematized matrix, produces a fine red powder along the failure surfaces. Some of the samples in Class 6 comprise mainly unaltered rock, with narrow veins of altered rock containing haematized material, sometimes with calcite.

The basic statistics of the uniaxial compressive strength for each of the failure type classes are given in Table 4 and the box and whisker plot is presented in Figure 6. Most of the samples are in the first three classes but there are thirty-four from Class 5. Only a few samples failed along a number of white veins or along a haematized vein. The data show that the strongest samples tend to be from Class 1 followed by Classes 2, 3. The weakest specimens failed along haematized material. 


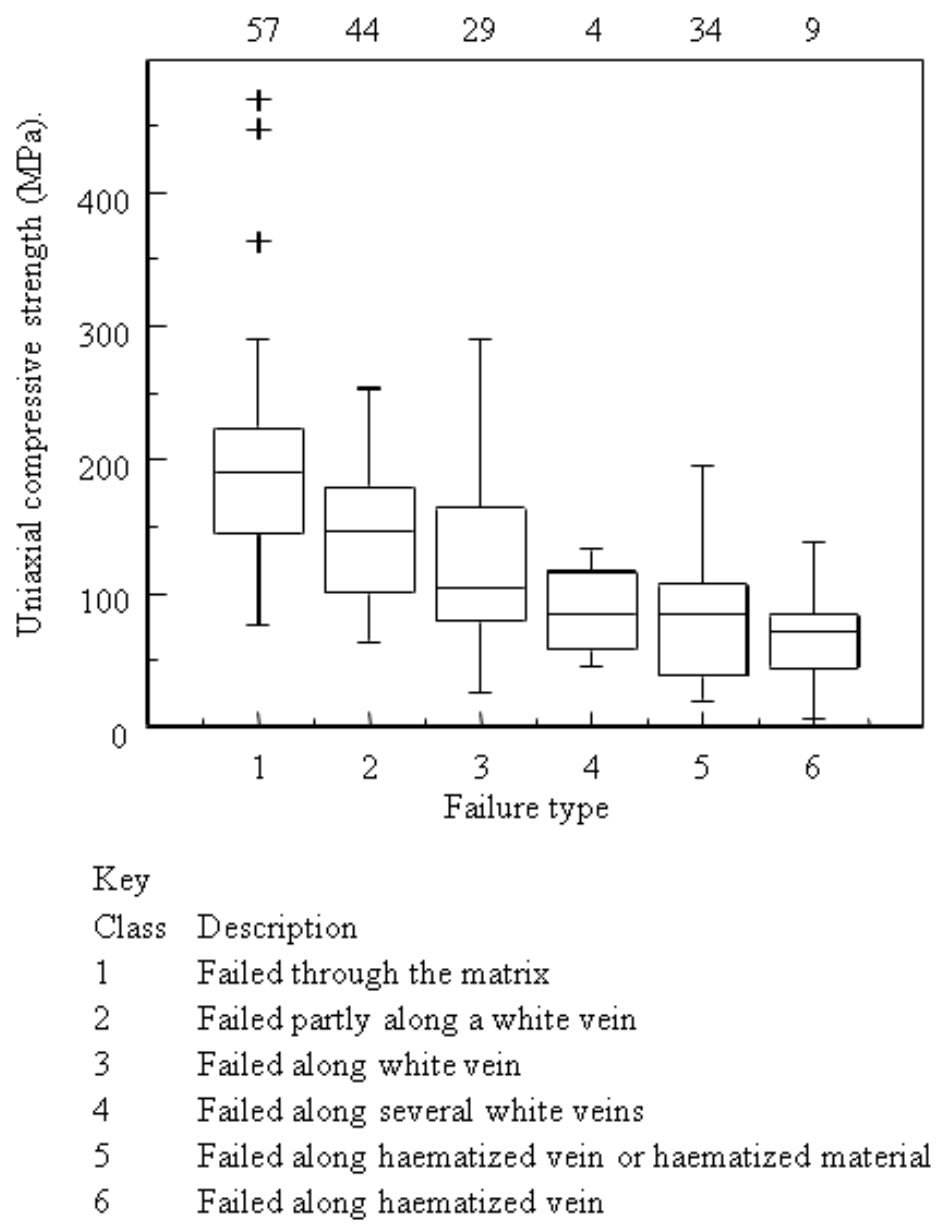

Figure 6. Box and whisker plot of uniaxial compressive strength differentiated by failure type.

Similar multiple box and whisker plots of effective porosity and sonic velocity are presented in Figures 7 and 8 respectively. Failure Classes 1, 2 and 3 have similar, generally low, effective porosity. Rocks that have been altered and reddened, Class 5, tend to have the highest effective porosity values. The plot for Class 6 suggests two different rock types; one of low effective porosity, typical of material from classes 1, 2 and 3, and the other of high effective porosity, similar to samples from class 5 . Figure 8 shows a similar but inverse distribution for sonic velocity. Classes 1,2 and 3 comprise mainly high sonic velocity, whereas class 5 has mainly lower values and class 6 has a number of higher values similar to those of classes 1, 2 and 3 and low values similar to class 5 .

The uniaxial compressive strength varies between classes 1, 2 and 3 but there is little difference in effective porosity and sonic velocity between these classes. The presence of the narrow carbonated or quartz veins is not detected either by the effective porosity or sonic 
velocity. Variation in strength within classes 2 and 3 may reflect different vein orientations and vein thicknesses as well as effective porosity.

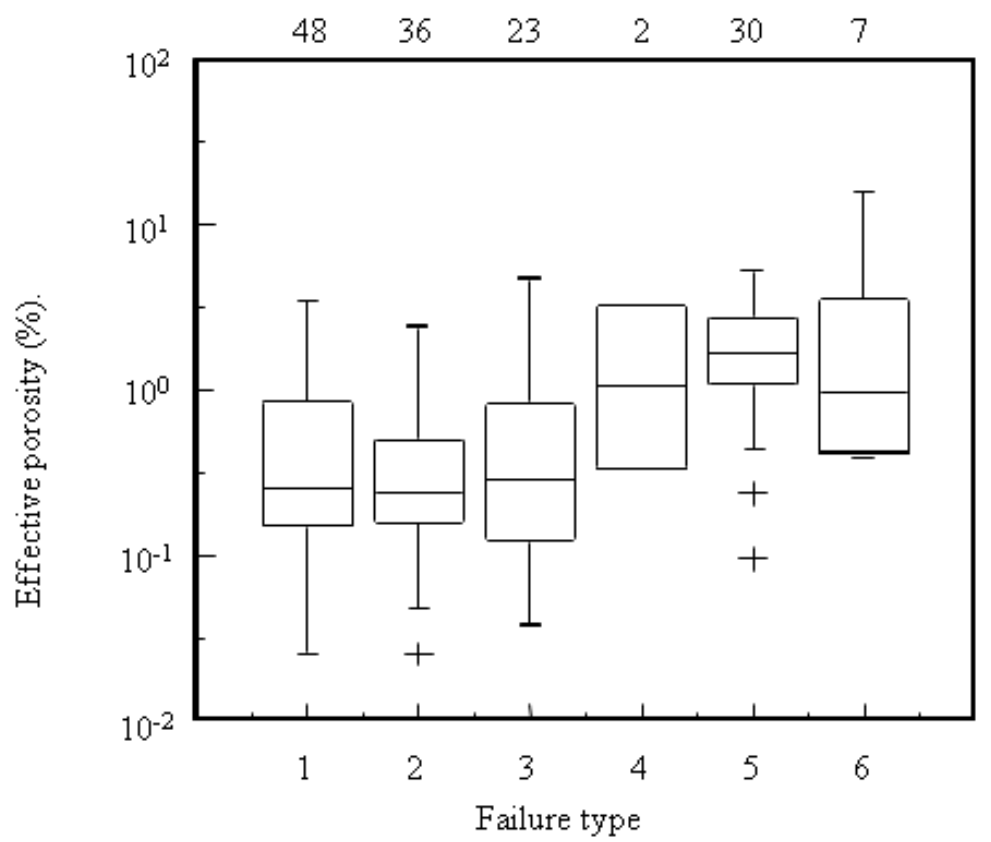

Figure 7. Box and whisker plot of effective porosity differentiated by failure mode (see Figure 6).

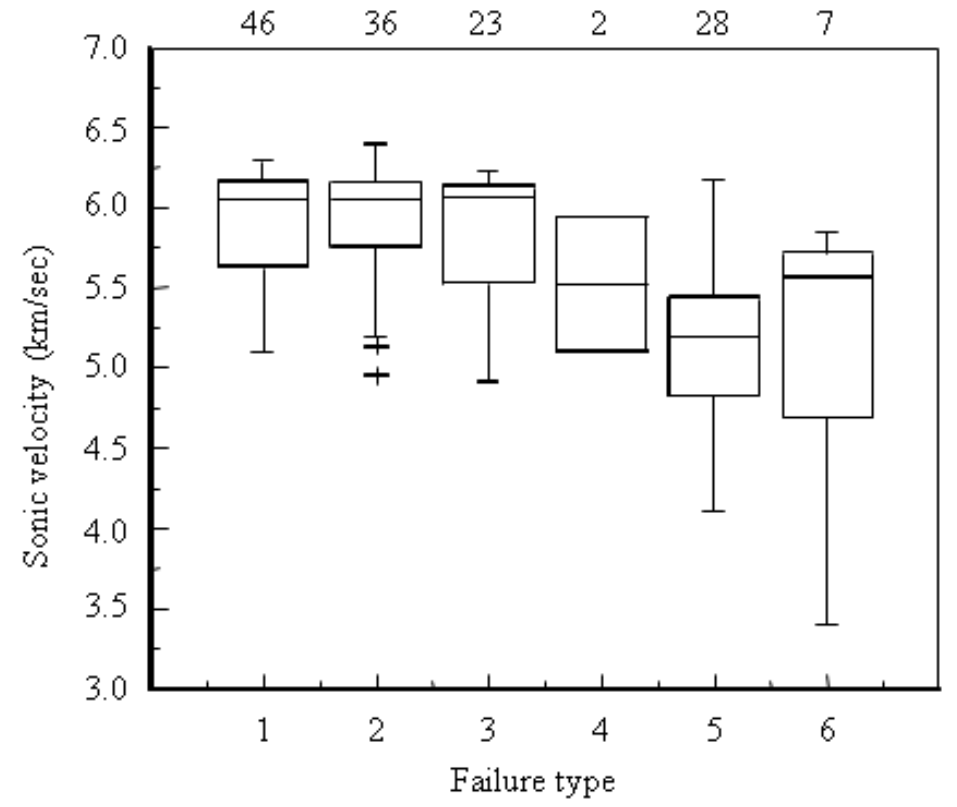

Figure 8. Box and whisker plot of sonic velocity differentiated by failure mode (see Figure 6).

The higher effective porosity and lower sonic velocity samples are usually associated with altered rock, particularly haematized material. However, samples in class 6 are of two types; lower effective porosity and higher sonic velocity samples that contain a fine, discrete, 
haematized vein within unaltered matrix, and higher porosity - lower sonic velocity samples that failed along haematized veins within haematized matrix.

Many of the faults and fractures present in the Borrowdale Volcanic Group are altered and haematized and many of the core breaks, a result of drilling disturbance are also haematized. Hence, it is important to identify zones of altered, veined and, in particular, haematized zones and haematized veins and to understand their effect on the strength of intact rock specimens and the rock mass.

The findings of this study agree with those of the McCann et al. (1990) in that the use of geophysical properties of rock to predict mechanical properties can only be done in general terms to give an indication of the variation of the property. No attempt should be made to obtain precise values of uniaxial compressive strength from sonic velocity determinations, though rock types could be classified qualitatively.

This study included those samples that were successfully prepared. Of the samples selected from these three boreholes nineteen failed prior to sample preparation, sixteen failed during preparation and two failed during non-destructive testing. Most of these samples were from altered rocks and some from fault zones. These samples were weak and likely to have had higher effective porosity and lower sonic velocity or contain a haematized vein. Hence, as with many laboratory studies of rock, there is a bias towards stronger rocks, as these are the samples that are successfully cored, prepared and tested.

\section{CONCLUSIONS}

The laboratory measurement of two hundred and seventy seven effective porosity, two hundred and sixty one saturated sonic velocity and one hundred and sixty one saturated uniaxial compressive strength on intact specimens from the Borrowdale Volcanic Group of Sellafield Boreholes 2, 4 and 5 showed that a majority had low to very low effective porosity, high sonic velocity and were 'very strong' to 'extremely strong'. However, a proportion of the values were of higher effective porosity, lower sonic velocity and lower strength.

Bivariate analysis showed that the sonic velocity increased with decreasing effective porosity when the effective porosity was greater than about $0.3 \%$. Below $0.3 \%$ the sonic velocity was fairly constant (about 6.1 to $6.3 \mathrm{~km} / \mathrm{s}$ ). The analysis of sonic velocity and uniaxial 
compressive strength showed a wide range of uniaxial compressive strength at higher sonic velocities. Uniaxial compressive strength varies considerably at low effective porosities (less than about 2\%). Variation of the uniaxial compressive strength at high sonic velocities and low effective porosities was probably due to structural differences between samples. The failure type of each uniaxial compressive strength test specimen was classified based on the material that failed. The strongest rocks tended to fail through the rock matrix, and the weakest rocks tended to fail through haematized material or along haematized veins. Effective porosity and sonic velocity could not distinguish between those samples that failed through the matrix and those that failed along discrete narrow veins. The presence of narrow haematized veins has a major effect on the intact rock strength.

\section{ACKNOWLEDGEMENTS}

The authors would like to thank the reviewers for their comments. This paper is published with the permission of the Director of Science of Nirex and the Director of the British Geological Survey (NERC).

\section{REFERENCES}

Ambrose, K., Patterson, M.G., Strong, G.E. \& Williamson, I.T.: The geology of Sellafield borehole 2. UK Nirex Ltd. Report No. 184. 1992a.

Ambrose, K., Patterson, M.G., Strong, G.E. \& Williamson, I.T.: The geology of Sellafield borehole 5. UK Nirex Ltd. Report No. 530. 1992b.

Anon.: Rock characterisation, testing and monitoring. International Society for Rock Mechanics. Editor E.T. Brown. Commission on testing methods, International Society for Rock Mechanics. Pergamon Press, London, 1981, p. 211.

Anon.: Code of practice for site investigation, BS 5930. British Standards Institute, London, 1999, p. 191.

Brereton, N.R.: Physical property relationships from Sites 765 and 766. Proceedings of the Ocean Drilling Program. Scientific Results, Volume 123, Paper 23. Argo Abyssal Plain/Exmouth Plateau. Sites 765-766, 28 August - 1 November, 1988. National Science Foundation and Joint Oceanographic Institutions. 1992, pp. 453-468.

Brereton, N.R. \& McCann, D.M.: A fresh look at predictive equations for compressional wave velocity-porosity. In: P.F. Worthington, (Ed.) Advances in core evaluation accuracy and precision in reserves estimation. Proceedings of the first Society of Core 
Analysts European Core Analysis Symposium. London, May 1990. Gordon and Breach Scientific Publishers. 1990, pp 270-298.

Brereton, N.R., Evans, C.J. \& Kingdon, A.: Hydrogeological and geotechnical rock property characterisation from geophysics. Proceedings of the Yorkshire Geological Society, 52, (2), 1998, pp 199-213.

D'Andrea, D.V., Fischer, R.L. \& Fogelson, D.E.: Prediction of compressional strength from other rock properties. United States Department of the Interior Bureau of Mines, Report of Investigations 6702. 1965.

Davies, N. \& Mellor, D.: Review of excavation disturbance measurements undertaken within the ZEDEX project: Implication for he Nirex Rock Characterisation Facility. In: Barla, G. (Ed.), Prediction and performance in rock mechanics and rock engineering, Eurock '96, Proceeding of ISRM International Symposium, $2^{\text {nd }}-5^{\text {th }}$ September, 1996, pp 13151322.

Glenn, W.E. \& Nelson, P.H.: Borehole logging techniques applied to base metal ore deposits. In: Hood, P.J. (ed.) Geophysics and Geochemistry in the Search for Metallic Ores. Geological Survey of Canada Economic Geology Report 31, 1979, pp 273-294.

McCann, D. M., Barton, K .J. \& Hearn, K.: Geophysical borehole logging with special reference to Altnabreac, Caithness. Institute of Geological Survey Report No. ENPU 81-11. 1981. British Geological Survey, Keyworth, Nottingham

McCann, D.M., Culshaw, M.G. \& Northmore, K.J.: Rock mass assessment from seismic measurements. In: Bell, F.G., Culshaw, M.G., Cripps, J.C. \& Coffey, J.R. (Eds.), Fields Testing in Engineering Geology. Geological Society Engineering Special Publication No. 6, 1990, pp 257-266.

Michie, U.: The geological framework of the Sellafield area and its relationship to hydrogeology. Quarterly Journal of Engineering Geology, 29, 1996. S13-S27.

Millward, D., Williamson, I.T. \& Ambrose, K.: The geology of Sellafield Borehole No. 4. Nirex Core Characterisation Series. UK Nirex Ltd Report No. 196. 1992.

Millward, D., Beddoe-Stephens, B., Williamson, I.T. Young, S.R. \& Petterson, M.G.: Lithostratigraphy of a concealed caldera-related ignimbrite sequence within the Borrowdale Volcanic Group of west Cumbria. Proceedings of the Yorkshire Geological Society, 50, 1994, pp 25-36.

NIREX.: Interpretation of Sellafield geotechnical laboratory test data. UK Nirex Ltd Report SA/97/017, prepared by British Geological Survey. 1997a. 
Paper: GEGE2166-RAD

NIREX.: Spatial heterogeneity of rock mass properties. UK Nirex Ltd. Report N. SA/97/021. 1997b.

Schlumberger.: Log interpretation principles and applications. Schlumberger educational services, Houston, Texas, 1989, p. 223.

Wood, AB.: A Textbook of Sound. G. L. Bell, London, 1941. 
Paper: GEGE2166-RAD

Table 1. Borehole data and stratigraphy.

\begin{tabular}{|c|c|c|c|}
\hline & $\begin{array}{c}\text { Borehole } 2 \\
\text { Depth } \mathrm{m} \text { above ground level }\end{array}$ & $\begin{array}{c}\text { Borehole } 4 \\
\text { Depth } \mathrm{m} \text { above ground level }\end{array}$ & $\begin{array}{c}\text { Borehole } 5 \\
\text { Depth m above ground level } \\
\end{array}$ \\
\hline National grid reference & (NY) 305543503412 & (NY) 305639503457 & $\begin{array}{c}(\mathrm{NY}) 305170503872 \\
54^{\circ} 25 \mathrm{~N} 18 \mathrm{ON}, 3^{\circ} 27 \mathrm{~N}\end{array}$ \\
\hline Latitude, Longitude & $54^{\circ} 25 \mathrm{~N} 03 \mathrm{ON}, 3^{\circ} 27 \mathrm{~N} 20 \mathrm{OW} 54$ & $4^{\circ} 25 \mathrm{~N} 05 \mathrm{ON}, 3^{\circ} 27 \mathrm{~N} 15 \mathrm{OW}$ & $22 \mathrm{OW}$ \\
\hline Fleming Hall Formation & -401.54 to -878.35 & -337.05 to -856.64 & -403.51 to -805.40 \\
\hline Longlands Farm Member & -401.54 to -757.59 & -337.05 to -720.13 & -403.51 to -571.75 \\
\hline Unnamed Member & -757.59 to -764.59 & -720.13 to -735.77 & -571.75 to -583.30 \\
\hline Sides Farm Member & Not present & Not present & -583.30 to -651.10 \\
\hline Town End Farm Member & -764.59 to 812.48 & -735.77 to -856.13 & -651.10 to -805.40 \\
\hline Brown Bank Formation & -812.48 to -1000.33 & -856.25 to -982.86 & -805.40 to -850.83 \\
\hline Bleawath Formation & -1000.33 to -1414.57 & -982.86 to -1254.00 base & -850.83 to -1254.00 base \\
\hline Broom Farm Formation & -1414.57 to -1425.96 & & \\
\hline Moorside Farm Formation & -1427.95 to -1604.00 base & & \\
\hline Intrusive rocks & $-773,-1028,-1193,-1223$ & $\begin{array}{r}-443.5,-662.5 \\
-713.7 \text { to }-720.1 \\
-846.64 \text { to }-851.96\end{array}$ & -763.2 to -766.7 \\
\hline
\end{tabular}


Paper: GEGE2166-RAD

Table 2. Basic statistical data

\begin{tabular}{|c|c|c|c|c|c|c|c|c|c|c|c|c|c|}
\hline \multirow[t]{2}{*}{ Parameter } & \multirow{2}{*}{$\begin{array}{l}\text { Number } \\
\text { of values }\end{array}$} & \multirow[t]{2}{*}{ Minimum } & \multirow[t]{2}{*}{ Maximum } & \multirow[t]{2}{*}{ Mean } & \multicolumn{9}{|c|}{ Percentiles } \\
\hline & & & & & 1 & 2.5 & 10 & 25 & 50 & 75 & 90 & 97.5 & 99 \\
\hline Effective porosity (\%) & 277 & 0.01 & 15.7 & 0.98 & 0.03 & 0.05 & 0.10 & 0.17 & 0.51 & 1.23 & 2.44 & 3.79 & 4.76 \\
\hline Sonic velocity $(\mathrm{km} / \mathrm{sec})$ & 261 & 3.4 & 6.39 & 5.69 & 4.76 & 4.59 & 4.97 & 5.37 & 5.84 & 6.11 & 6.19 & 6.24 & 6.29 \\
\hline
\end{tabular}

Table 3. Regression and correlation results

\begin{tabular}{llccrrr}
\hline \multicolumn{1}{c}{$\mathrm{x}$} & \multicolumn{1}{c}{$\mathrm{y}$} & $\begin{array}{c}\text { sample size } \\
\mathrm{n}\end{array}$ & Equation form & $\mathrm{a}$ & \multicolumn{2}{c}{$\begin{array}{c}\text { Regression coefficient } \\
\mathrm{r}^{2}\end{array}$} \\
& & & & & & \\
Effective porosity & Sonic velocity & 256 & $\mathrm{y}=\mathrm{aLog}_{10}(\mathrm{x})+\mathrm{b}$ & 0.78 & 5.428 & 0.750 \\
Effective porosity & Sonic velocity & 256 & $\mathrm{y}=\mathrm{ax} \mathrm{b}^{\mathrm{b}}$ & 5.4008 & -0.0615 & 0.722 \\
Effective porosity & Sonic velocity & 256 & $\mathrm{y}=\mathrm{ae}^{\mathrm{bx}}$ & 5.974 & -0.0557 & 0.703 \\
Sonic velocity & U.C.S. & 142 & $\mathrm{y}=\mathrm{ae}^{\mathrm{bx}}$ & 0.783 & 0.882 & 0.533 \\
Sonic velocity & U.C.S. & 142 & $\mathrm{y}=\mathrm{ax}^{\mathrm{b}}$ & 0.292 & 4.79 & 0.531 \\
Effective porosity & U.C.S. & 144 & $\mathrm{y}=\mathrm{ae}^{\mathrm{bx}}$ & 159.52 & -0.291 & 0.534 \\
Effective porosity & U.C.S. & 144 & $\mathrm{y}=\mathrm{ax}{ }^{\mathrm{b}}$ & 90.82 & -0.363 & 0.501 \\
\hline
\end{tabular}

